\title{
INTEGRATING ECOSYSTEM THEORIES - GRADIENTS AND ORIENTORS AS OUTCOMES OF SELF-ORGANIZED PROCESSES
}

\author{
FELIX MÜLLER \& FRANZISKA KROLL \\ Institute for the Conservation of Natural Resources, Christian-Albrechts University of Kiel, Germany.
}

\begin{abstract}
This paper discusses the ecological gradient principle and shows interrelations of this concept with several approaches of ecosystem analysis and theory. After a general description of ecosystem self-organization, ecological gradients are introduced as emergent ecosystem properties, their characteristics are explained, and different gradient types are distinguished. On this basis, the gradient principle is related to some other theoretical approaches of ecosystem comprehension: hierarchy theory, network theory, and thermodynamics. Thereafter, while observing ecosystem development, gradients are related to orientor theory, and the roles of disturbances are discussed. Few outcomes of the gradient principle for environmental management are listed, reaching from indicator derivation, integrity utilization to ecosystem service-based valuations. Finally, Bossel's basic orientor concept is used to show a gradient-related linkage between environmental and human systems.

Keywords: ecosystem theories, ecosystem gradients, self-organization, ecological orientors, ecological integrity, ecosystem services.
\end{abstract}

\section{INTRODUCTION}

The following pages are dedicated to our late colleague and friend Enzo Tiezzi. Enzo has been an inspiring analyst and supporter of ecosystem theories and a brilliant expert in closing the linkages between thermodynamics and ecosystem ecology. Besides his excellent scientific recognitions, Enzo Tiezzi was always open for interdisciplinary conceptions and he was extremely constructive in identifying and understanding interrelationships at all levels of science. Enzo was a wonderful host of ecosystem workshops, fostering dialogues between colleagues from very distant origins, offering an extraordinary hospitality and deep friendship. In his book 'Steps towards an evolutionary physics' ([1], pp. 61-62), Enzo Tiezzi has written the following sentences: 'Generation of patterns and shapes is a ubiquitous phenomenon in nature. It occurs from microscopic to macroscopic level in living and non-living systems alike. At every level of complexity, common features seem to relate ecosystem dynamics with the development or organization of biological and chemical systems. Understanding pattern generation is thus inherent to understanding the notion of complexity in open systems."

With this paper we want to underline Enzo Tiezzi's recognition of self-organized patterns, focusing on the significance of gradients in ecological and human-environmental systems. The article provides a broad overview of different approaches trying to illuminate the applicability of the gradient principle in ecosystem analysis and management. We will touch many different items that provide a huge range of interesting information and knowledge. Regrettably, many of the important details of those concepts cannot be discussed in detail, because the article will concentrate on the interrelations between them. The basic hypothesis is related to concentration profiles in and between ecological entities: ecosystems are self-organized networks of structural and functional gradients, which interact on different hierarchical levels. Within this assumption our main objectives are the following:

- To provide an overview of the gradient-based comprehension of ecosystems,

- To link the perception of ecosystem gradients with other approaches of ecosystem theories,

(C) 2011 WIT Press, www.witpress.com

ISSN: 1755-7437 (paper format), ISSN: 1755-7445 (online), http://journals.witpress.com

DOI: 10.2495/DNE-V6-N4-318-341 
- To provide information on applied concepts of the gradient approach in environmental management, and

- To show gradient-based linkages between ecosystem theory and human-environmental systems analysis.

The structure of the paper includes a sequence of propositions related to ecosystem selforganization and ecological gradients that are comprehended as results and causes of self-organized processes. Thereafter, the gradient principle is correlated with different ecosystem theories and their concepts to understand ecosystem development. Finally we will discuss the applicability of the approach for environmental management and for the comprehension of human-environmental systems. A practical application can be found in the strongly related article 'Can the principle of gradients be applied for human systems?' by Kroll and Müller [2] in this journal.

\section{ECOSYSTEM SELF-ORGANIZATION}

To consider the creation of ecosystem gradients, the following questions have to be discussed briefly: what is self-organization, which are the conditions of self-organized processes, and what are their outcomes? To introduce this topic we might conduct the well-known diffusion- 'Gedankenexperiment' (see Fig. 1): imagine a container with different chambers. In the chambers there are different gas molecules. Now we open the valves between the chambers, and the result will be a homogeneous distribution of the different elements. The system has achieved thermodynamic equilibrium which is the most probable state [3-5]. During this dissipation process the existing gradient - the concentration profile within the whole box - has gone extinct, and we can observe an overall disorder. Amazingly, in open systems, there is the potential to create new gradients, without manipulations from outside. This process - the spontaneous creation of macroscopic structures from microscopic disorder - is called dissipative self-organization [6-8]. It works hand in hand with the noninfluenced creation of new concentration profiles. Therefore, self-organization is closely correlated with gradient formation: the whole system obtains a complex structure on the base of interrelations between the parts.

Of course besides our interpretation many other definitions of self-organization are available. Some of them are documented in Table 1. The unifying nucleus of these aspects can be aggregated to three points:

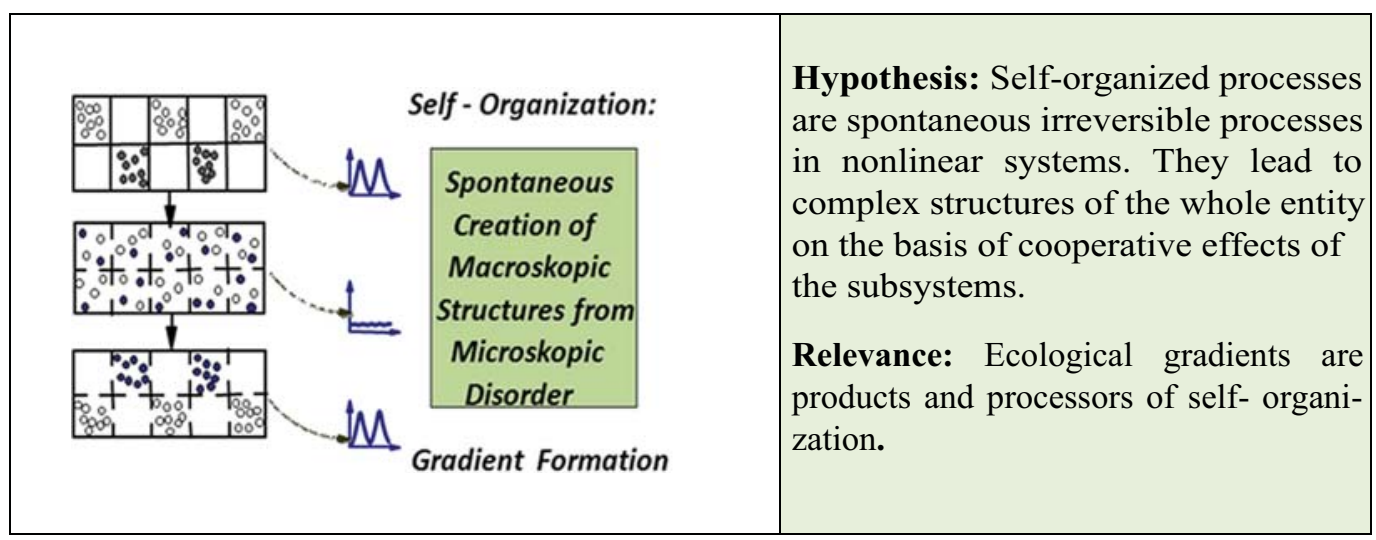

Figure 1: Illustrating the basic outcomes of self-organized processes. 
- The structure of the system arises without explicit pressures from outside.

- The structure is created due to internal interactions and cooperation.

- Self-organization leads to new - emergent - properties that are related to the interactions of the whole system.

Self-organized processes have been observed in many different systems. For example in physics and chemistry, laser processes [9], convection clusters in Benard cells [10], and the BelousovZhabotinsky reaction [11] have been studied intensively. Referring to biological systems, morphogenesis [12], flocking behavior of animals [13], evolutionary dynamics [14, 15], and the climate system $[16,17]$ have been fields of intensive synergetic research.

The respective processes only function under certain constraints in open systems which are able to exchange energy, matter, or information with the environment. Necessarily, we need an input of usable energy, which is called exergy [5]. It is the energy fraction that can be transformed into mechanical work. This captured exergy is used for irreversible processes, for example growth or reproduction. Thereby, parts of the captured energy are transformed into structures and information, and the system will utilize other fractions of the input exergy for its energetic maintenance [26]. The produced entropy fraction, which can no more be used in the system is released into the environment. As a consequence, the open system will enlarge its distance from thermodynamic equilibrium on the base of self-regulated internal control mechanisms. It will build up a structure of spatial and functional gradients. These processes are limited to some basic conditions (see Table 2).

Table 1: Different comprehensions of self-organization [18, 19].

An der Heiden ([20], p. 72)

Ebeling ([21], p.118)

Krohn and Küppers ([22], p. 165)

Krohn and Küppers ([22], p. 395)

Roth ([23], p. 169)

Salthe ([24], p. 323)

Von Förster ([25], p. 88)
Those features and structures of a system that are induced by the dynamical interrelationships of the components are self-organized features.

Self-organized processes are irreversible processes in nonlinear dynamical systems that lead to complex structures of the whole entity on the basis of cooperative effects of the subsystems. The resulting structures are not forced from the outside but arise due to internal interactions.

All systems in which the causes for changes are induced internally and in which external influences are not significant are self-organized systems. Such systems exhibit boundaries that delimit the system from its environment.

A system is self-organized if its spatial and temporal structures are created by their internal dynamics only.

Self-organized processes are such physical and chemical processes that lead to an ordered state or an ordered sequence of states from a broad range of potential initial conditions.

Self-organization is a dynamic process in natural systems, which leads to an increase of complexity, size, influence, and throughput.

Self-organized processes are processes that cause an increase of the degree of complexity within a limited area due to self-referential interactions. 
Table 2: Criteria and conditions for self-organizing processes [21, 27].

\begin{tabular}{|c|c|}
\hline Openness & $\begin{array}{l}\text { Self-organizing systems exchange energy, matter, and } \\
\text { information with their environments. }\end{array}$ \\
\hline Import of convertible energy & $\begin{array}{l}\text { Self-organizing systems need energy imports that } \\
\text { are transferable into mechanical work (exergy). }\end{array}$ \\
\hline Suitable quantities of energy input & $\begin{array}{l}\text { Self-organizing systems can develop and maintain only } \\
\text { within a certain energetic window. }\end{array}$ \\
\hline Internal energy transformations & $\begin{array}{l}\text { Self-organizing systems transform the imported energy in } \\
\text { physical and chemical, anabolic and catabolic processes. }\end{array}$ \\
\hline Export of non-usable energy & $\begin{array}{l}\text { Self-organizing systems produce non-usable energy forms } \\
\text { as a re]sult of the irreversible processes. This energy } \\
\text { fraction is exported into the environment (entropy). }\end{array}$ \\
\hline Distance from equilibrium & $\begin{array}{l}\text { Self-organizing systems build up internal structures and } \\
\text { thereby increase their distances from thermodynamic } \\
\text { equilibrium. }\end{array}$ \\
\hline Non-linearity & $\begin{array}{l}\text { Self-organizing systems can only develop if the changes of } \\
\text { one state variable lead to nonlinear changes of other state } \\
\text { variables. }\end{array}$ \\
\hline Amplification & $\begin{array}{l}\text { Self-organizing systems exhibit high fluctuations when their } \\
\text { states approach phase transitions. }\end{array}$ \\
\hline Self-referentiality and cooperation & $\begin{array}{l}\text { Self-organizing systems are not regulated by external } \\
\text { forces. Their dynamics arise as a result of the internal } \\
\text { interactions. }\end{array}$ \\
\hline Hierarchies and constraints & $\begin{array}{l}\text { Self-organizing systems are internally coordinated by } \\
\text { processes on different scales. }\end{array}$ \\
\hline Stability & $\begin{array}{l}\text { Self-organizing systems are able to buffer minor inputs } \\
\text { when their dynamics are situated near steady state. }\end{array}$ \\
\hline Historicity and irreversibility. & $\begin{array}{l}\text { Self-organizing systems develop on the basis of irreversible } \\
\text { processes. Therefore, their actual state can only be } \\
\text { understood in its historical context. }\end{array}$ \\
\hline
\end{tabular}

Besides the mentioned open energetic framework, self-organization only can occur as a product of cooperation between the parts of a system. Testing the respective criteria of Table 2 for the case of ecosystems will show that they are suitable concerning all items: ecosystems are self-organized systems.

\section{GRADIENTS AS ECOSYSTEM PROPERTIES}

In this chapter the focal questions will be: how can we better understand the relationships between structural and functional units of ecological systems? How can the spatiotemporal results of selforganized processes be demonstrated?

\subsection{Introducing gradients}

If we want to investigate an ecosystem, we have to take into account many different structural features as well as ecosystem processes like water flows, carbon and energy storages, or nutrient 
dynamics. The gradient viewpoint offers a suitable starting point for the aspired integration: on the one hand gradients are structural items, creating concentration profiles along a distance. They describe differences in the quantities or qualities of specific variables in dependence of their positions in an observer-defined environment. On the other hand they are causes for all processes within the system, because the flows are usually directed from sources - areas of high concentrations - to sinks, which are regions with lower concentrations (see Fig. 2). The higher the difference between these locations, the higher is the potential of the respective flows. These processes are regulated by internal resistances.

We can use the example of soil erosion to demonstrate these contexts: the gradient (X) is built by selected positions along a slope that can be characterized by the slope length and its inclination. This gradient provides the potential $(\mathrm{V})$ for erosive transports throughout heavy runoff processes $(\mathrm{J})$. It can be degraded by erosion events with high precipitation intensities. The efficiency of the event is regulated by the resistant site factors like erodibility, soil cover, or soil treatment $(\mathrm{R})$.

The resulting ecological gradients are products of three main process classes (see Table 3 ). Transport processes provide gradients, for example, in geomorphological patterns, in vertical distributions

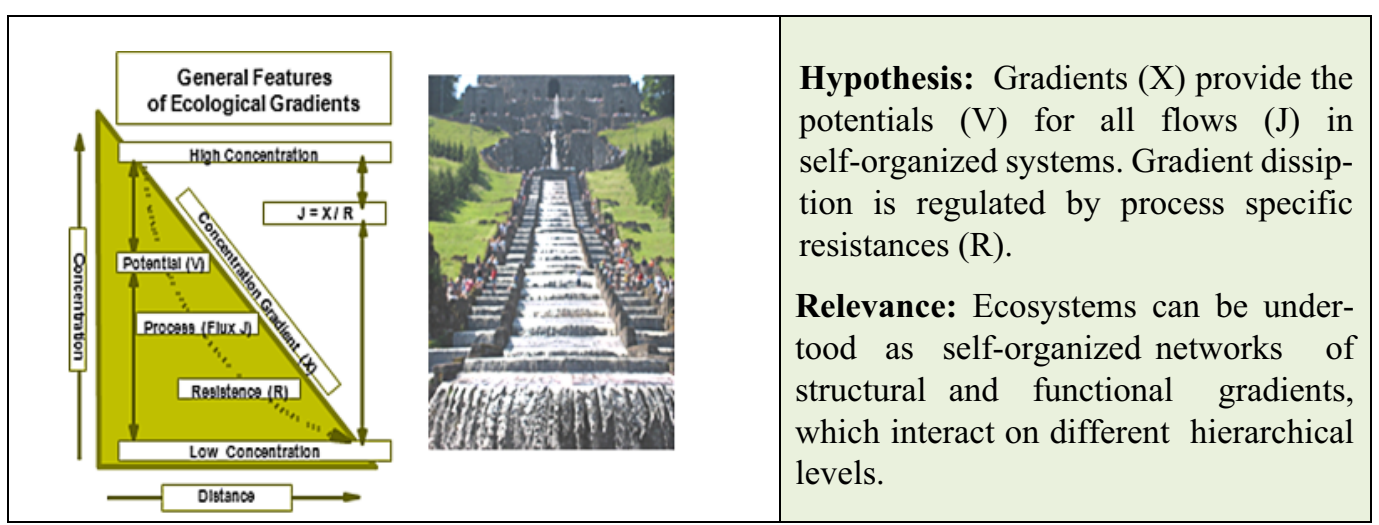

Figure 2: Illustrating the basic features of ecological gradients.

Table 3: Some environmental processes of gradient creation (process types and examples).

\begin{tabular}{|c|c|c|}
\hline A. & $\begin{array}{l}\text { Gradients are } \\
\text { consequences of } \\
\text { mechanical transport } \\
\text { processes }\end{array}$ & $\begin{array}{l}\text { Geological, mineralogical processes (e.g. by tectonics) } \\
\text { Geomorphological dynamics (e.g. by wind, water, ice) } \\
\text { Pedological development (e.g. by leaching, soil aggregation) } \\
\text { Biological translocation processes (e.g. by litter fall) }\end{array}$ \\
\hline B. & $\begin{array}{l}\text { Gradients are } \\
\text { consequences of } \\
\text { filtering processes }\end{array}$ & $\begin{array}{l}\text { Sorting due to distinct porosities in soils } \\
\text { Molecule distinctions due to adsorption and desorption processes } \\
\text { Sorting of particles due to solution and precipitation processes }\end{array}$ \\
\hline & $\begin{array}{l}\text { Gradients are } \\
\text { consequences of active } \\
\text { biotic accumulation } \\
\text { processes }\end{array}$ & $\begin{array}{l}\text { Photosynthesis, respiration, specific food intake, food web } \\
\text { flows, detritus formation, and human actions }\end{array}$ \\
\hline
\end{tabular}


of soil characteristics, or through biological processes. A second class of processes which produce specific gradients is related to filtering processes. For example, in soils porosities and surface features regulate the adsorption or desorption of nutrients, as well as solution and precipitation dynamics of chemical compounds. Finally there are active accumulation processes, like photosynthesis, food intake, food web flows, or detritus formation.

\subsection{Gradients in ecological research}

In ecology, mainly landscape scientists have investigated such patterns of concentration profiles intensively, mostly mapping vegetation distributions. Gradients are the focal items of Whittaker's theory of vegetation distribution [28]. The methodology of gradient analysis [29] interrelates the profiles of environmental factors, population structures, and community characteristics. Similar concepts are often used in autecology, correlating the ecological preferences of species with anthropogenic, biotic, or abiotic concentration profiles. Also macro ecology [30] typically refers to gradients, and many investigations of landscape ecology are based on an analysis of gradients: heterogeneities, boundaries, ecotones, or patch dynamics implicitly are consequences of ecological gradients.

\subsection{Gradient characteristics}

Gradients can be characterized by their direction, steepness, steadiness, dynamics, or their processual potentials. According to the interrelated potentials, all flows, transfers, or movements can be viewed as reactions that form, maintain, or degrade gradients. Applying these relations to ecological processes, a general, thermodynamics-based equation can be set up [3, 31]: the ecological flux rates $\mathrm{J}_{\mathrm{i}}$ can be induced by external signals or inputs. Fluxes thus are functions of the ecological gradients $\mathrm{X}_{\mathrm{i}}$ and the material constants $\mathrm{L}_{\mathrm{i}}$ that control the adjustment of the gradient-induced potentials for mechanical or biochemical work:

$$
\mathrm{J}_{\mathrm{i}}=\mathrm{L}_{\mathrm{i}} \mathrm{X}_{\mathrm{i}}
$$

This very general equation can be applied to several physicochemical processes in ecosystems on the basis of well-known equations, such as:

- Heat transfer processes: the flow of heat (I) results in the proportions of the heat conduction coefficient $(\lambda)$ and the temperature gradient $(\mathrm{dT})$ along a spatial distance $(\mathrm{dx})$ :

$$
\mathrm{I}_{\mathrm{h}}=\lambda(\mathrm{dT} / \mathrm{dx})
$$

- Water transfer processes: the amount of water flowing through an area (Q) can be formulated as a function of the water potential gradient $(\mathrm{d} \psi)$ along a distance $(\mathrm{dl})$ and the hydraulic conductivity $\mathrm{k}$ :

$$
\mathrm{Q}=\mathrm{k}(\mathrm{d} \psi / \mathrm{dl})
$$

- Diffusive transfer processes: The flow of ions in a solution (I) is a function of the difference of their concentrations $(\mathrm{dC})$ along a distance $(\mathrm{dx})$ and the specific features of the medium, which are represented by the diffusion coefficient (D); dC/dx defines the gradient within Fick's law:

$$
I_{d}=-D(d C / d x)
$$

Thus, the fundamental processes of the ecosystemic water, matter, and energy budgets are based on gradients, whereby the material constants play an important role for the development and the maintenance of the system: if they have a high influence on the flows, the site-specific resistances 
will provide negative feedbacks. Thus the steady states of the flow schemes can be maintained, and the prevailing interior disequilibria can be kept in a metastable state. In the other case, instabilities will occur and the system will develop toward another attractor state.

If $\mathrm{L}_{\mathrm{i}}$ develops toward a higher value, there is a high propensity for accumulating processes that can enlarge the existing gradients.

Summarizing, gradients are products of self-organized accumulation procedures and driving forces of ecological processes. Taking into account thermodynamic arguments, even ecosystem existence and the general trends of ecosystem development are based on the presence of disequilibria and gradients, because in a homogeneous distribution there are no structure-based potentials for living processes and autonomous, self-organized dynamics [10, 32-34].

\subsection{Types of ecosystem gradients}

In ecosystems we can distinguish two basic types of gradients: structural and functional gradients. They are separated on the basis of their reference dimensions: although the structural gradients are concentration profiles along a spatial axis, the functional gradients refer to the flow schemes between sources and sinks (for examples see Table 4). The general features of these types are the following:

- Structural gradients: From the conventional point-of-view, ecosystem structure displays the spatiotemporal determination of selected system components, their abundance, and their arrangement within the biotope [35]. Therefore, structural gradients arise from the spatial

Table 4: Examples for different gradient types observed in the Bornhöved Lakes District (for detailed descriptions see [41]).

\begin{tabular}{|c|c|}
\hline Gradient type & Examples \\
\hline Structural gradients & $\begin{array}{l}\text { Soil parameters in a beech forest } \\
\text { Vegetation patterns at hedgerows } \\
\text { Vegetation patterns in wetlands } \\
\text { Bathymetry of Lake Belau } \\
\text { Vertical gradients of soil fauna }\end{array}$ \\
\hline Functional gradients: & $\begin{array}{l}\text { Energetic gradients maize vs. alder carr } \\
\text { Carbon allocation processes } \\
\text { Soil water gradients in arable land } \\
\text { Evapotranspiration and energy balance Water balances } \\
\text { Chemical soil gradient } \\
\text { Element concentrations in soils } \\
\text { Energy balances at different scales } \\
\text { Bioconcentration factors of plants }\end{array}$ \\
\hline Energetic gradients & $\begin{array}{l}\text { Food consumption in aquatic food web } \\
\text { Limnetic energy cascades }\end{array}$ \\
\hline Hydrological gradients & $\begin{array}{l}\text { Hydrological gradients and abundances } \\
\text { Vertical groundwater flow patterns }\end{array}$ \\
\hline Chemical gradients & $\begin{array}{l}\text { Nitrogen fluxes through shore types } \\
\text { Nitrogen balances in lake Belau }\end{array}$ \\
\hline
\end{tabular}


patterns of ecosystem elements and subsystems. Furthermore, ecosystem structure determines the potentials for interactions that operate within the structural patterns. In this context, biodiversity can also be comprehended as a gradient system; it can be directly compared to the gas molecule depictions from Fig. 1: if there is a low diversity, there is homogeneity and consequently no significant spatial gradients can be spanned. If there are many differences, high heterogeneity and variability, spatial gradients will turn up, positively correlated with the variation coefficients and negatively linked to dominant identities.

- Functional gradients: Functions are selected relations between ecosystem components, forming patterns of ecosystem processes [36]. They are related to flows, storages, and regulations between ecosystem compartments. The functional gradients arise along three process groups with typical developmental traits throughout the complexifying ecosystem succession (see also Chapter 5):

- Energetic gradients: Exergy capture (uptake of utilizable energy) is rising during the undisturbed development, the total system throughput is growing (maximum power principle, see [37]) as well as the articulation of flows (ascendency, see [38]). Due to the high number of processors and the growing amount of biomass, the energetic demand for maintenance processes and respiration is growing as well (entropy production, see [39]).

- Hydrological gradients: Throughout the undisturbed development of ecosystems and landscapes, more and more elements have to be provided with water. This means that especially the water flows through the vegetation compartments show typical orientor behavior [40] because they demonstrate an important prerequisite for all cycling activities in terrestrial ecosystems, namely the water uptake by plants, which is regulated by the degree of transpiration.

- Chemical gradients: Imported nutrients are transferred within the biotic community with a growing partition throughout undisturbed ecosystem development. Therefore the biological nutrient fractions are rising as well as the abiotic carbon and nutrient storages, the cycling rate is growing, and the efficiencies are improved. As a result, the loss of nutrients is reduced.

Consequently, ecosystem organization in fact can be understood as a self-organized network of structural and functional gradients, which interact on different hierarchical levels.

\section{GRADIENTS AND ECOSYSTEM THEORIES}

Theories are representations of the proved knowledge of a scientific discipline, consisting of abstract descriptions and sets of hypotheses. As this paper is also related to the Prigogine Award, ecosystem theories can be introduced with respect to some winners of this prize. Taking into consideration the ideas of Prigogine, Sven-Erik Joergensen [5] has developed the ecological law of thermodynamics. It states that ecosystems tend to optimize exergy storage, meaning that they utilize the captured usable energy to enlarge their distance from thermodynamic equilibrium. Therefore, ecosystems increase their structural heterogeneity as well as their functional storage capacities. Both of these items are related to internal gradients, be it the information content, or be it biomass, nutrient contents, or carbon pools. In addition to Joergensen's theory, the group of Enzo Tiezzi [1] has investigated the embodied energies - the emergy - of ecosystems and correlated it to Joergensen's results. Two other Prigogine prize winners have investigated ecosystems from a network perspective. They have quantified the energy flows through the food webs of different ecosystems. Although Benhard Patten [42] has shown the dominance of indirect effects in ecosystem development, Robert Ulanowicz [43] has proposed the variable ascendency to characterize the long-term trajectory of community development. Taking the viewpoint of gradients, these concepts can be adopted if the ecosystem cycles 
are unfolded. In that case it becomes visible that in both pathways, the production based food web and the detritus based food web, the flows of energy follow the gradients of biomass, as has been suggested before. In the following chapters the linkages of the gradient approach will be highlighted referring to three selected theoretical approaches, which are hierarchy theory, thermodynamics, and network theory.

\subsection{Gradients and hierarchy theory}

Self-organized processes provide an enormous complexity, in the lab as well as in nature or in society. To understand the interrelations between the multiple gradients, we have to reduce complexity on a reliable theoretical basis. Let us look at a self-organized system from the viewpoint of signal transfer: we will find very slow processes like the growth of whales in the ocean, and very fast actions like the generation turnover of microorganisms. The slow processes mostly operate on broad spatial extents - the whales need very large areas for their survival, while the fast ones can be assigned to smaller spaces - that would be the pore volumes of sediment aggregates for the bacteria (see Fig. 3). The fascinating feature of these hierarchies arises from the self-created regimes of constraints: the lower level units must react on changes of the higher levels. In the other direction, there are filters, thus the higher level does not immediately react on changes of the lower niveaus. This constellation operates during phases with small perturbations. In case of instabilities the hierarchies are broken and the system of hierarchical constraints functions no more [44-47].

Taking these cybernetic ideas into account, many sorts of hierarchies can be exemplified. We can look at the biological sequence from organelles over cells to tissues, organs, populations, or communities and ecosystems. And we will see that in fact there is not only a hierarchy of structural gradients, but also a hierarchy of regulations. While the lower levels, the small units provide the biological potential, the higher levels - which are formed by the lower ones - provide reductions of the degrees of freedom for the small scale processes.

Also the ecological processes can be distinguished on this hierarchical basis. There are the relatively short life trajectories of single organisms, long-lasting dynamics of populations, processes in successions, or the long-term ecosystem evolution. And if we concentrate on an interdisciplinary ecosystem analysis, we will find that the geologists work about long time scales and need large

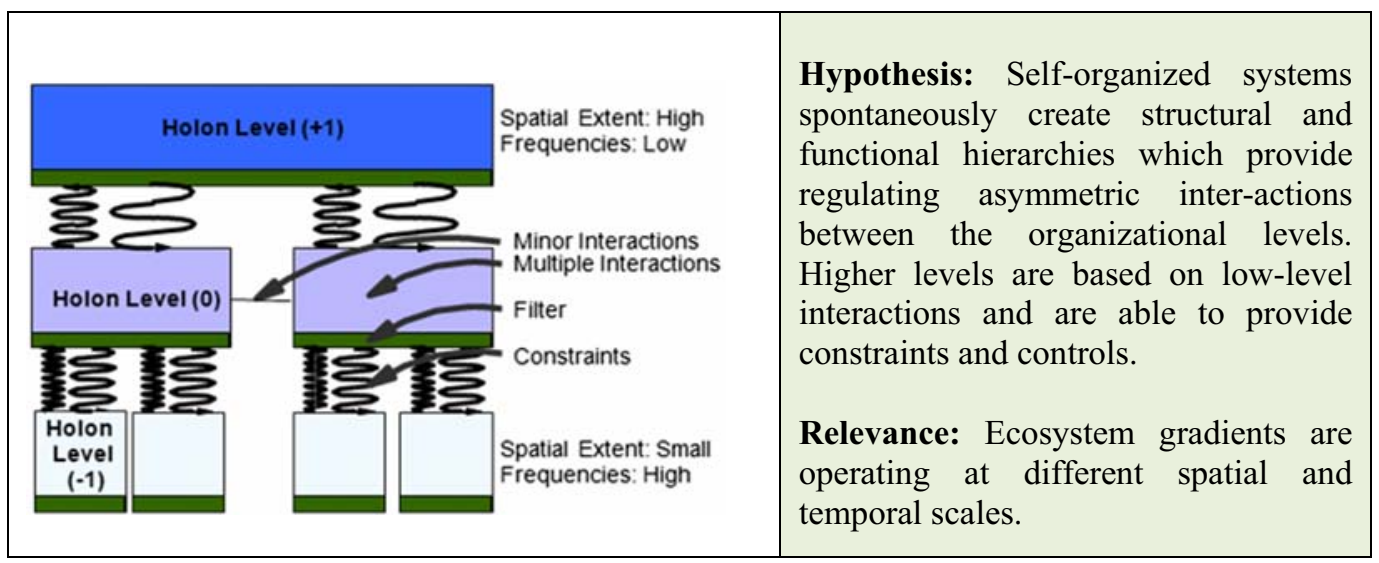

Figure 3: Illustrating the basic principles of hierarchy theory. 
extents for their analyses. The soil structure depends on the geological setting, but it shows a higher variety and higher dynamics. The vegetation changes even more quickly with smaller extents, the fauna can develop even faster, and in the end we return to the microorganisms, with extremely fast reactions on small spaces. All of these sub-systems create structures, pools, and thus gradients; and the interactions between these gradients - the flows - operate with a respective sequence of frequencies. Therefore, we can comprehend ecosystems as hierarchies of gradients and gradient-related interactions:

- Gradients are basic structural characteristics of holons, representing functionally autonomous entities (which are built up by inferior gradients) as well as subsystems of superior organizational units.

- Ecosystems thus are organized by an ensemble of gradients that are interacting through highly interrelated processes of gradient construction and gradient dissipation.

- An ecological hierarchy can be comprehended as a partly ordered set of gradients that are interrelated by asymmetric interactions.

- The scale of a gradient determines its functionality as a single step in the whole systems' control pattern.

\subsection{Gradients and thermodynamics}

Several items of the thermodynamic approach to ecosystems have already been mentioned. The initial question is related to the energetics of ecosystems: there is an input of exergy, the exploitable energy fraction that can perform mechanical work. It can be quantified taking thermodynamic equilibrium as a reference state. The ongoing processing of this energy leads to spontaneous gradient formations (see Fig. 4). On the one hand: the amount of energy invested into these structures - the embodied energy - can be represented by the emergy of the system [37]. On the other hand, several physiological processes are necessary to maintain the built-up structures and the functional linkages. As a result of these processes the ecosystem produces $\mathrm{CO}_{2}$, water vapor, and heat and it emits reflected or heat-based radiations; all of these components are exported into the environment being no more usable for the ecosystem. The respective energy fraction indicates the entropy production

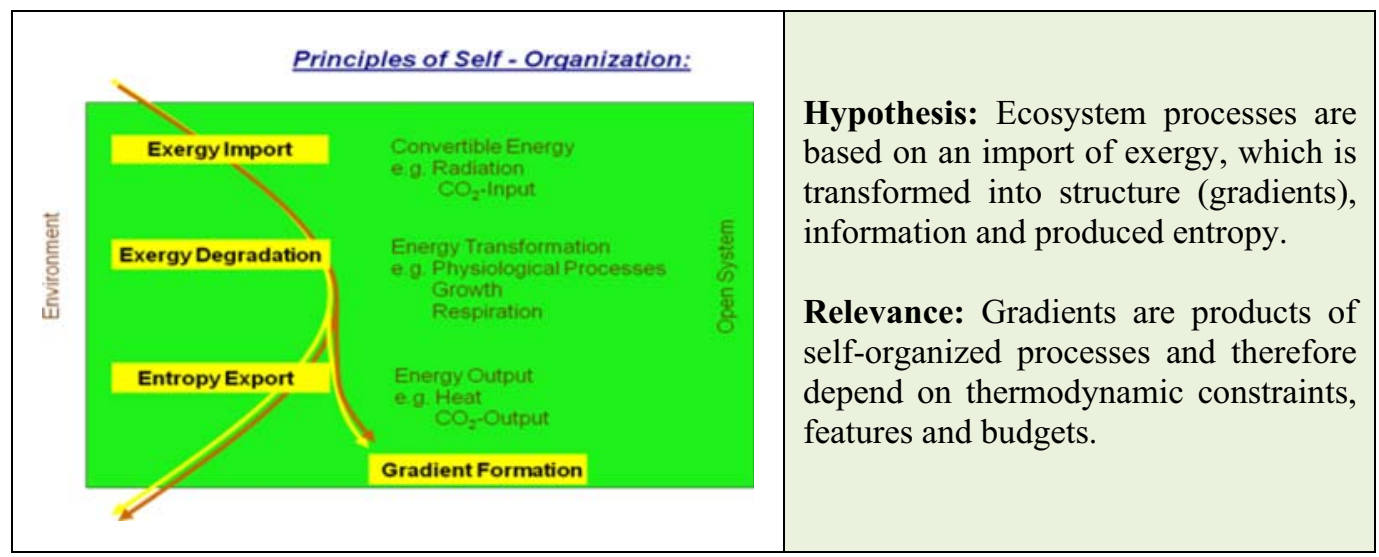

Figure 4: Summarizing some thermodynamic fundamentals of gradient creation. 
of the ecosystem. The relations between those processes show a regular directionality during the self-organized processes of ecosystem development, which have been summarized in two sets of hypotheses:

- The thermodynamic non-equilibrium principle of Kay and Schneider is related to flow and storage of exergy $[5,32,48]$. The principle states that a system exposed to a flow of exergy from outside - which can be indicated by the energetic gradient imposed on the system - will be displaced from its optimum operating domain due to the exterior inputs. The response of the system will be a resistance against being moved from the attractor, by organizing itself so as to degrade the imported exergy - i.e. to reduce or destroy existing gradients - as thoroughly as the prevailing circumstances permit. The further the system is moved from equilibrium, the larger the number of all opportunities which are accessible and consequently, the more effective it will be in exergy degradation [32].

- While Schneider and Kay are stressing the system's degradation capacity, Joergensen [48] puts emphasis on the development of gradients and structures. The respective formulation of his exergy optimization principle is the following: "If a system receives a throughflow of exergy, the system will utilize this exergy to move away from thermodynamic equilibrium. If the system is offered more than one pathway to move away from thermodynamic equilibrium, the one yielding most stored exergy, i.e. with the most ordered structure or the longest distance from thermodynamic equilibrium by the prevailing conditions, will have a propensity to be selected" ([48], p. 166).

Although at a first glance these principles seem to be contradictory, in fact they are focussing the same object from different viewpoints and thus they are compatible to a very high degree: ecosystems are operating within the energetic gradient of solar radiation. The higher this is and the more suitable the site conditions are, the more solar exergy can be taken up by the plants. This imported exergy is converted into several fractions, which generally can be distinguished into three pools: biomass, nonliving resources, and structures, related to the system's information. Although these pools are built up in a non-equilibrium, non-homogeneous manner (creating gradients), certain energetic fractions have to be used for the maintenance of the gradient structure: via respiration, transpiration, or nutrient loss, the imported exergy is converted into non-usable energy fractions (entropy production) throughout the degradation processes. Moreover, the more complex the structure is (the more exergy is stored and the more gradient features can be found), the more exergy has to be degraded to keep it alive. Therefore, by integrating these principles, the focal hypothesis reads: Living systems are degrading and utilizing external gradients by the self-organized formation of a hierarchy of nested internal gradients in correspondence with the energetic environment of the system.

\subsection{Gradients and network theory}

Network theory is trying to investigate the linkages among ecosystem compartments and the implications of the respective relationships. The transactions can be exchanges of energy, material, or information, which produce a certain flow pattern and an organizational structure [49]. Figure 5 shows two examples of network illustration: Although the analysis of energy flows often ends in very complex network models and graphs [42], an aggregation, e.g. of the biomass of different trophic levels can provide another idea of the gradient approach: following the active exergy accumulation by photosynthesis, the subsequent flows follow a simple gradient through the trophic cascade, which includes recycling of the detritus store, and therefore promotes several indirect effects within the food web and several features which are changing throughout ecosystem development [50-53]. 


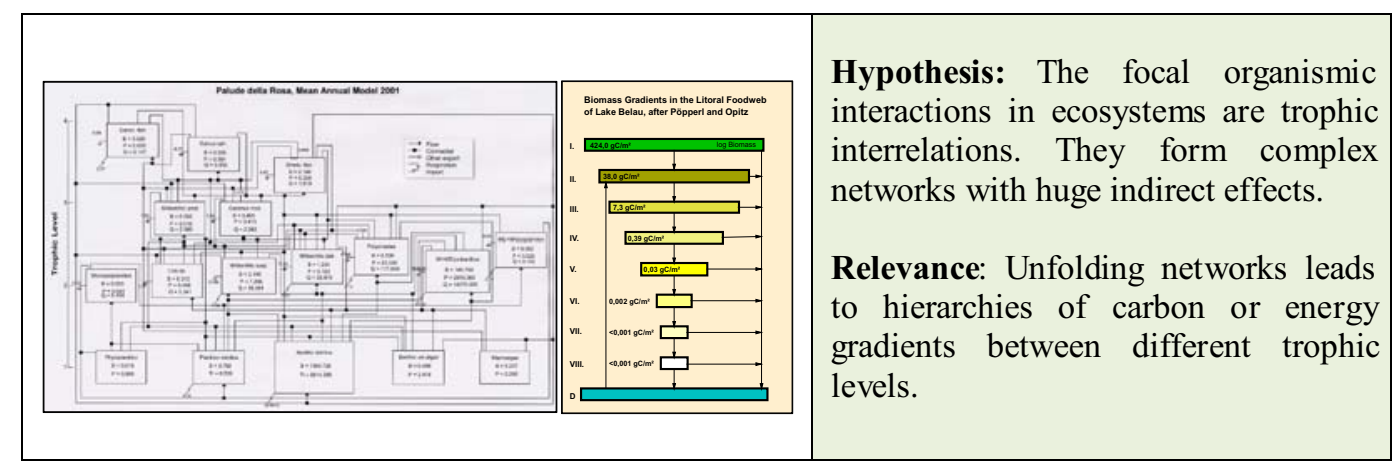

Figure 5: Summarizing some ideas from network theory and their consequences from a gradientrelated viewpoint. The figures in the left box show a food web model of the Lagoon of Venice, which has been kindly provided by Lucca Palmeri and an aggregation of the carbon stocks in different trophic levels of Lake Belau produced by Rainer Pöpperl and Sylvia Opitz.

\section{GRADIENTS AND ECOSYSTEM DEVELOPMENT}

The theories that have been sketched in the Chapter 4 have one important point in common: they are all related to growth and development of ecosystems, and they are all correlated with optimization principles [43].

These ideas have been aggregated in orientor theory $[18,26,34,54,55]$. The focal hypothesis of this concept is that during undisturbed self-organized developments, ecosystems tend to maximize complexity, up to a certain level, which is determined by the specific site conditions. The respective propositions are founded on empirical findings from succession analysis and investigations of ecosystem dynamics. There are several variables which can be used to describe such a 'directed' development. They are called orientors. These orientors can be distinguished into several groups. For example we can observe thermodynamic orientors, such as exergy capture, exergy degradation, entropy production, exergy flows, or exergy storage. From an ecophysiological viewpoint it can be stated that there is a reduction of loss, an increase in the cycling index, and an increase in the internal flows within the system; the changes of flow schemes can be represented by network and information theoretical orientors, such as direct/indirect effect, network utility, network homogenization, or ascendency $[52,56]$. Looking at ecosystem structures it has been observed that heterogeneity, diversity, and connectedness are optimized during undisturbed development. This trend is correlated with community based orientors, like niche diversity, the performance of symbiontic relationships or the body size of the living organisms. Last but not least, due to these dynamics, the emergence of gradients and the complexity of interrelations between them increase steadily.

Thus, we can keep in mind that self-organized processes regularly are accompanied by increases of complexity and related features, if the system is not disturbed. This leads to mature ecosystem states with a very high diversity and internal connectivity. Such ecosystem states are very often seen as the aspired conditions of an ecosystem from a conservational viewpoint: we can find many different species, there is a very high amount of biomass, and the systems seem to be very well-regulated. Regrettably this is also the ecosystem state with the highest risk, if the external constraints are changing. We have to take into account that the enormous amount of interrelationships is correlated with very strong mutual dependencies. Thus the change in one element of such a system can provoke extreme impacts into the whole structure: increasing connectivity is highly correlated with decreasing flexibility.

Taking into account the gradient approach it can be summarized that during undisturbed succession, the number of gradients is steadily increasing, as well as the interrelations between them. 


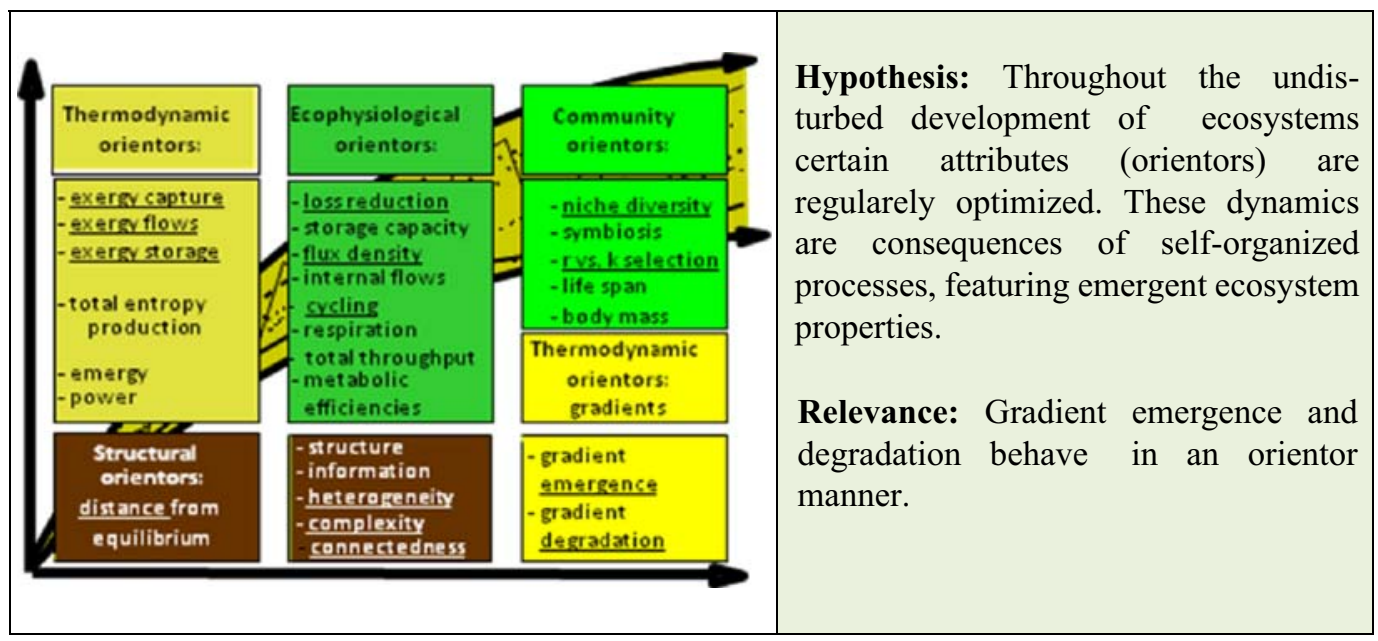

Figure 6: Illustrating some key orientor functions in ecosystem development.

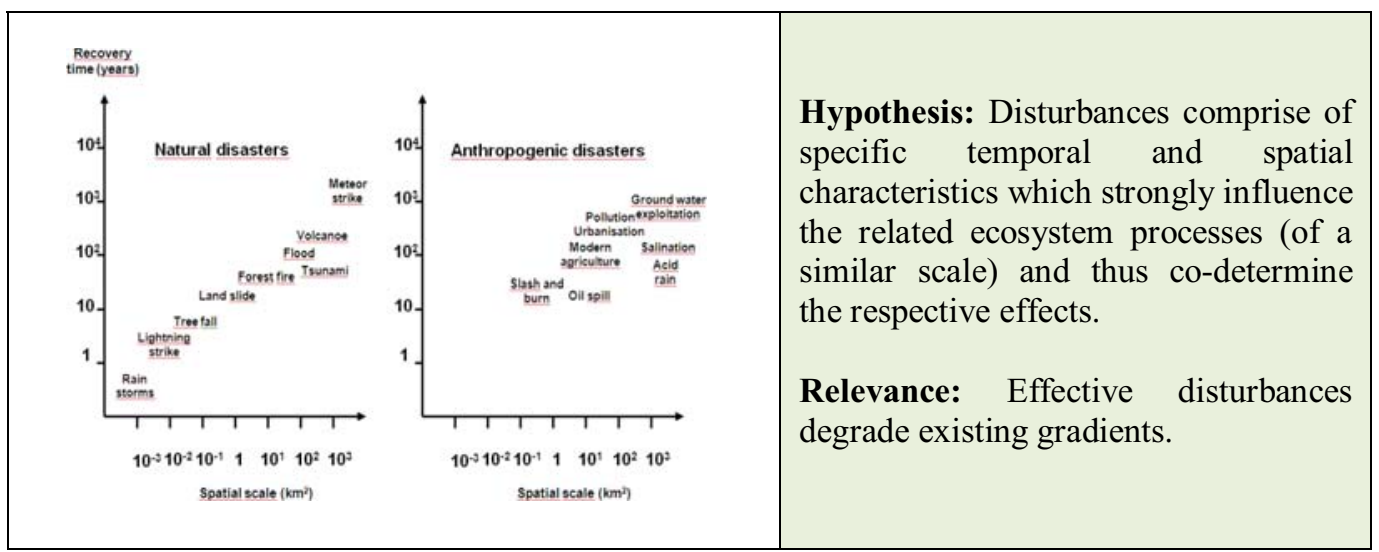

Figure 7: Illustrating some basic relations of disturbances. At the left side the spatial and temporal characteristics of some natural and anthropogenic disasters are depicted, following Vitousek [57], Di Castri and Hadley [58], Joergensen et al. [26].

This also implies that the demand for energetic maintenance to continue with that complexifying development steadily increases if no disturbances appear.

During the histories of ecosystems many 'discrete events that disrupt ecosystems, community, or population structure and change resources, substrates, or the physical environment', disturbances after Picket and White [59] occur, which modify the idealized orientor behavior: the created gradient structure is affected, gradient features break down, and the system has to find a new operating state (Fig. 7). The effects of disturbances are also related to the developmental stage of the system. Holling [60] has proposed to look at ecosystem development in an adaptive-cycle manner (Fig. 8). The development starts with a pioneer stage, where we have low connectedness and low exergy storage. Thereafter a very long phase follows during which the complexity steadily rises until we reach the conservation stage. This period could be called the orientor-optimization phase. We have to keep in 


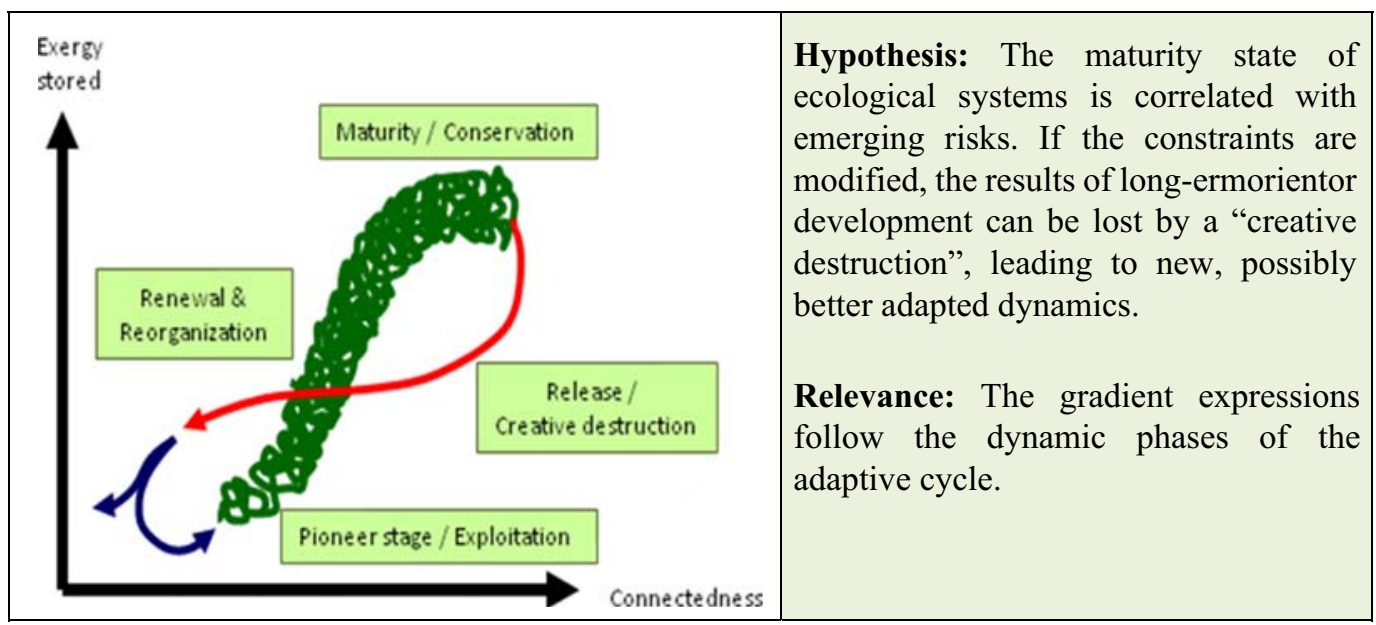

Figure 8: Illustrating the basic dynamic conditions within the adaptive cycle metaphor.

mind that the system is operating within this trajectory for the longest time of its existence. Due to the extreme connectivity and mutual dependency, the mature states become brittle, and if the constraints are changing, e.g. due to disturbance or climate change, a breakdown of the system can occur. Very rapidly the structure is dissipated, the stored exergy is lost, and the developmental stage is set down to a new starting point. We have to be aware that during such destructions, the gradients that have been built up in long-term processes are degraded and that the system of stabilizing hierarchical constraints is broken [61].

Holling has called this development creative destruction, because the reorganization phase provides new chances for the system to be better adapted, and to find a new trajectory that will again lead to long-term processes of orientor optimization [62]. If we apply hierarchy theory at this point, we can imagine that destruction in fact may be creative: a sequence of subsequent adaptive cycles, changing between construction and destruction can be the basis for very long-term optimizations; thus, a local breakdown can be part of global complexifying development.

\section{GRADIENT DYNAMICS AND ECOSYSTEM MANAGEMENT}

In this chapter some outcomes of ecosystem theories for environmental management will be sketched. Thus the focal question is: are the thermodynamics-based concepts also applicable to describe human-environmental relations, and can we comprehend social-ecological systems as self-organized units? The forthcoming text will propose some attempts, starting with the DriversPressures-State-Impact-Response (DPSIR) indicator approach and concentrating on its ecosystem related components integrity (state) and ecosystem services (impact), including the idea of overall basic orientors as joint descriptors of human and environmental systems.

The ecosystem approach of the CBD (http://www.cbd.int/ecosystem/) has successfully integrated some outcomes of ecosystem theories, and it correctly asks for an integration of ecosystems and human systems for sustainability management. Thus, several groups have tried to bring together the ideas about ecosystem health, biodiversity, and ecological integrity with socioeconomic entities [63-65]. Starting with a restrained concept we can apply the DPSIR approach [66] to landscape management problems (Fig. 9). We can use this model and try to quantify its components by indicators in different case studies. The DPSIR concept starts with a new land use structure, which imposes 


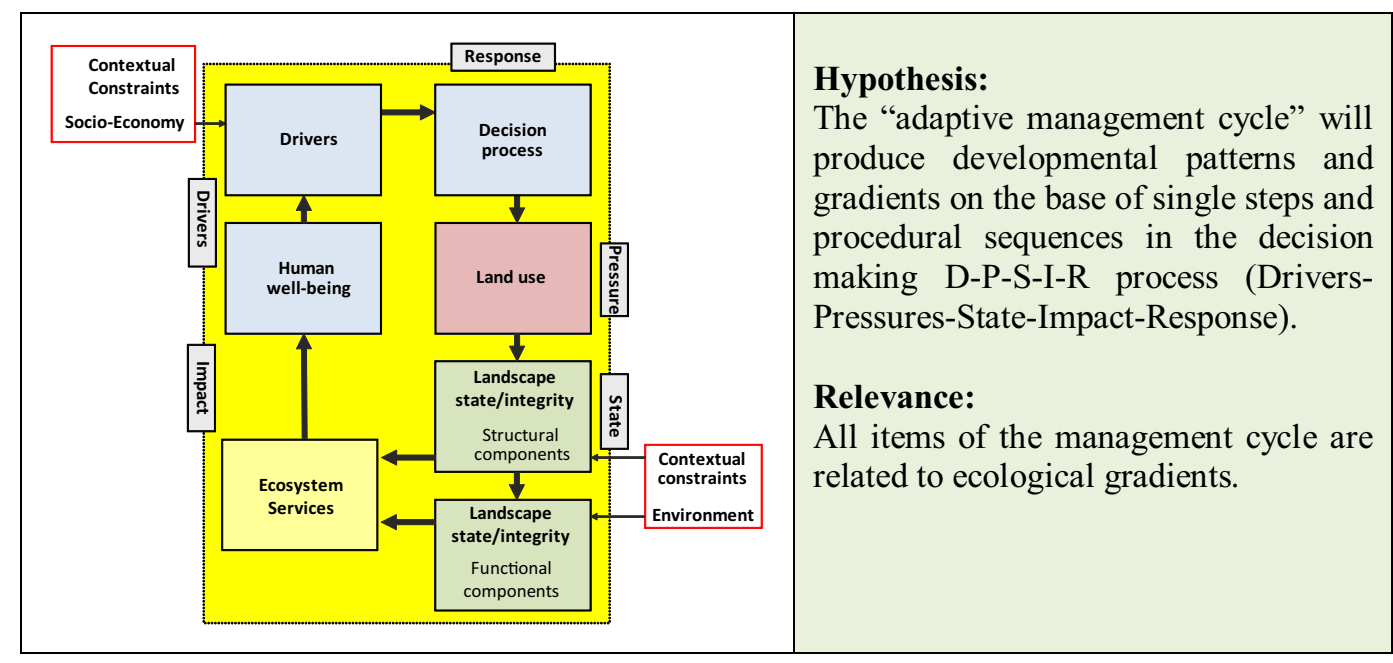

Figure 9: Illustrating an adapted DPSIR management cycle.

pressures on landscape integrity from a structural as well as a functional point-of-view. As a consequence of the altered ecosystem state, the provision of ecosystem services is modified and following the ideas of the Millennium Assessment (http://www.maweb.org/en/Synthesis.aspx), this has impacts on human well-being. Such changes modify the motivations - the drivers - of the actors, provoking a decision making process - the response - and thus, eventually changing the land use strategy again. This adaptive management cycle is hierarchically constrained by socioeconomic and environmental influences from outside. In this context we should be aware that all mentioned management steps are related to the performance of structural and functional patterns, thus all management components provide an analytical perspective on all sorts of ecological and socioeconomic gradients. For the conception of a consequent application of the ideas of ecosystem self-organization, it is important to note that both integrity and ecosystem services provide linkages between environmental issues and socioeconomic items. Therefore, a systemic view should be based on an expansion of the integrity concept toward a linkage with ecosystem services.

The DPSIR component 'state' can be described as an ecosystemic feature. Contributing to the overall idea of sustainable development, there are two major systems-based approaches of ecosystem protection. On the one hand, ecosystem health mainly refers to the preservation of ecosystem functions [63]. The second holistic management guideline is ecosystem integrity. The objective of integrity is to preserve those processes and structures that are essential prerequisites of the ecological ability for self-organization [67]. We can also utilize Kay's definition [68] which pronounces that, "an ecosystem has integrity if it retains its complexity and capacity for self-organization and sufficient diversity, within its structures and functions, to maintain the ecosystem's self-organizing complexity through time."

Resuming these concepts as guidelines, ecosystem management strategies should be based upon several of the values and qualities that have been stated before:

- Ecosystems are self-organized systems. All disturbances and management measures therefore influence the self-organizing capacity of these systems, mostly reducing the degrees of freedom for essential developmental processes. 


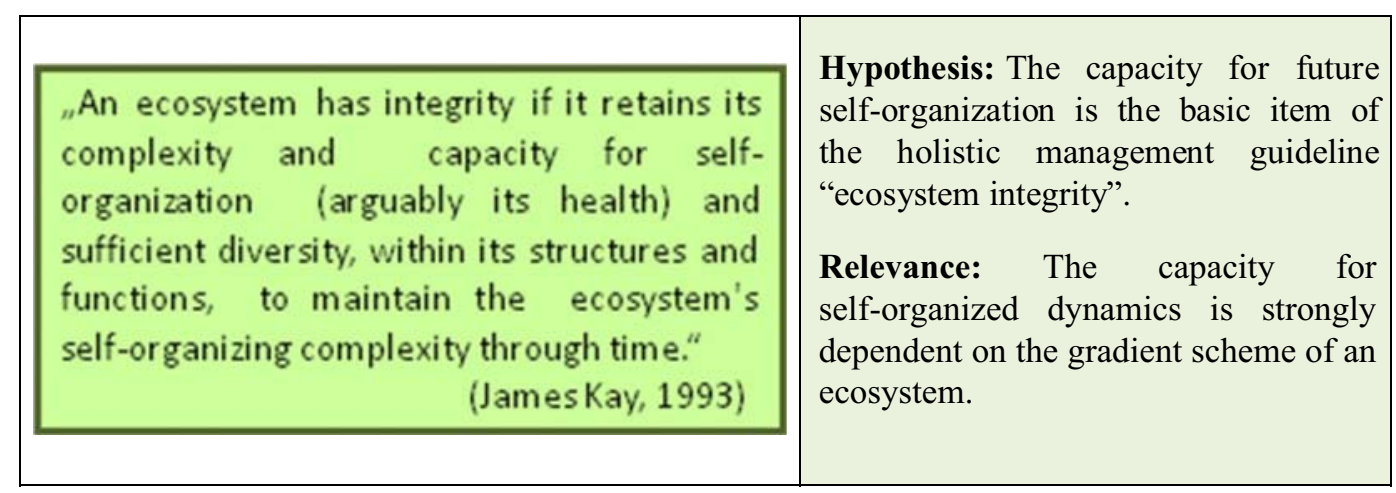

Figure 10: A definition of ecosystem integrity.

- Management should not be restricted to either structural items or functional units but should focus on the integration of these interdisciplinary spheres.

- Management should be aware of complexity and take into account that indirect effects are more significant than direct relationships.

- Management should take into account that different processes operate on different scales and should not neglect a consideration of long-term dynamics.

- Management should consider the effects of activities on adjacent and other ecosystems.

- Management should realize that local decay can be part of global progress. It should consider the system's resilience and adaptability and recognize that change is inevitable.

- Management should be aware that ecosystems are parts of human-environmental systems. Thus human use of an ecosystem should be optimized without damaging it.

- Management should enable the system to move forward in an orientor manner:

- Try to enhance exergy capture and the export of degraded exergy.

- Try to optimize storage capacities and minimize nutrient losses.

- Support cycling processes.

- Support the system's efficiencies, e.g. by enhancing transpiration.

- Allow the system to complexify and increase its heterogeneity.

- Management should be aware that ecosystems function on the basis of gradients which need long time spans to develop. Their degradation can be interrelated with enormous environmental risks.

These are challenging requirements. One question is how can we observe the outcome of management measures in a quantitative mode? Several groups have proposed indicators to represent the demands stated above. One result was a small set of indicators which are as a whole capable of describing the state of ecosystem self-organization, reflecting ecosystem structures as well as functions. In a first case study [69] we could base the resulting diagram on intensive measurements in the Ecosystem Research Project in the Bornhöved Lakes District (see Fig. 11). It made obvious the systemic differences of long-term land use, distinguishing a forest and a field, which have been divided 100 years ago. It is visible that the farmer is optimizing his yield, the primary production (exergy capture). But that objective is correlated with reductions of most other indicator values. 


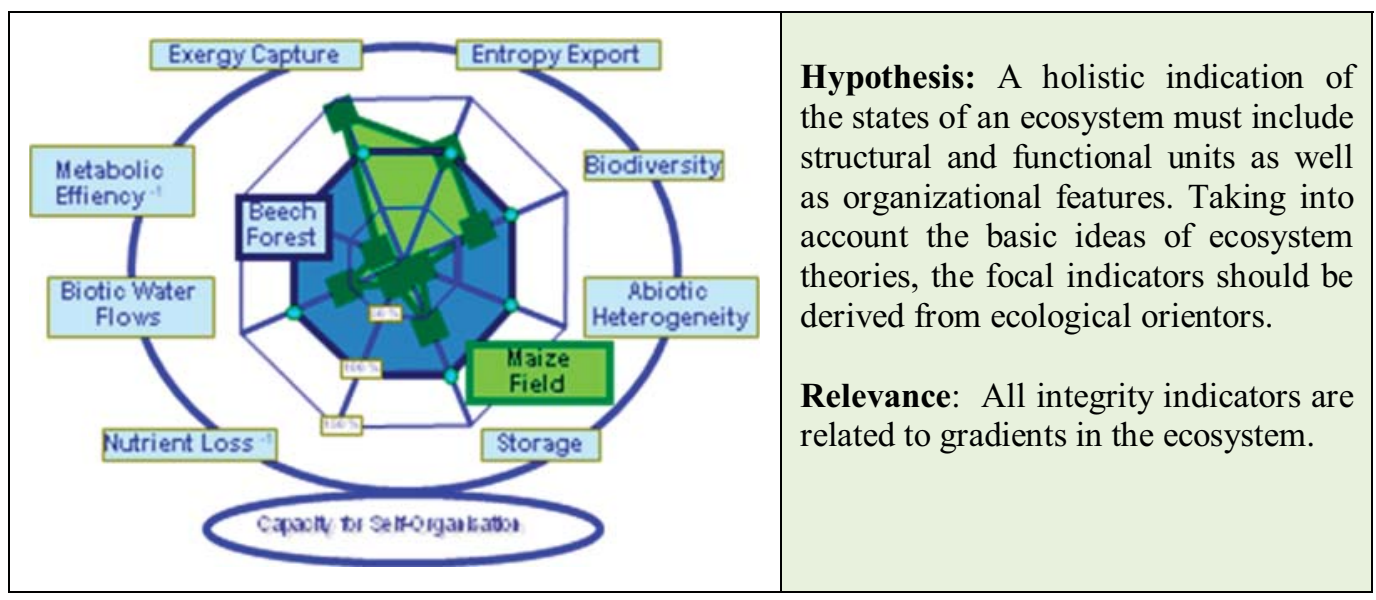

Figure 11: Ecosystem indicators to represent ecosystem integrity.

In several case studies $[67,70,71]$ we could find a close relationship between the key indicators from Fig. 11 and the gradient approach. For example:

- Exergy capture was indicated by primary production, which is nothing else than the creation of biomass gradients.

- Metabolic efficiencies quantify the relative degradation which is necessary for gradient creation and maintenance.

- Biotic water flows follow the hydrological gradients between soil and atmosphere and they are constraints for the matter cycling processes.

- Storage capacity can also be called gradient maintenance.

- Nutrient loss is the result of gradient dissipation, e.g. by mineralization.

- Heterogeneity and biodiversity refer to the horizontal gradients of parameter patterns, and

- Entropy export refers to exergy degradation due to metabolic demands, like respiration, but it can also be a proxy for stress, e.g. by extreme microbial respiration rates.

So far, it can be stated that the thermodynamic concepts of ecosystem development can be employed to characterize ecosystem states. But regrettably that is not sufficient for developing ecosystem management strategies. Coming from ecosystem analysis and ecosystem theories it is of course very interesting to make the necessary step of linking environmental impacts with human attitudes. Therefore the indications of ecological integrity have to be coupled with ecosystem services. These are the goods and benefits which nature provides for human welfare [71]. Usually three service types are distinguished: provisioning services (e.g. food, fiber, or drinking water), regulating services (e.g. climate regulation, nutrient regulation, or air quality regulation), and cultural services (e.g. recreation, aesthetics, or social relations). Recently this concept has experienced a big run of conceptions from many different disciplines, and several researchers and managers are thinking of restricting environmental evaluations on the ecosystem service indicators.

We have applied ecosystem service quantification methods in some of our case studies [72], like a wetland restoration study which is sketched in Fig. 12. We have found that valuable information 


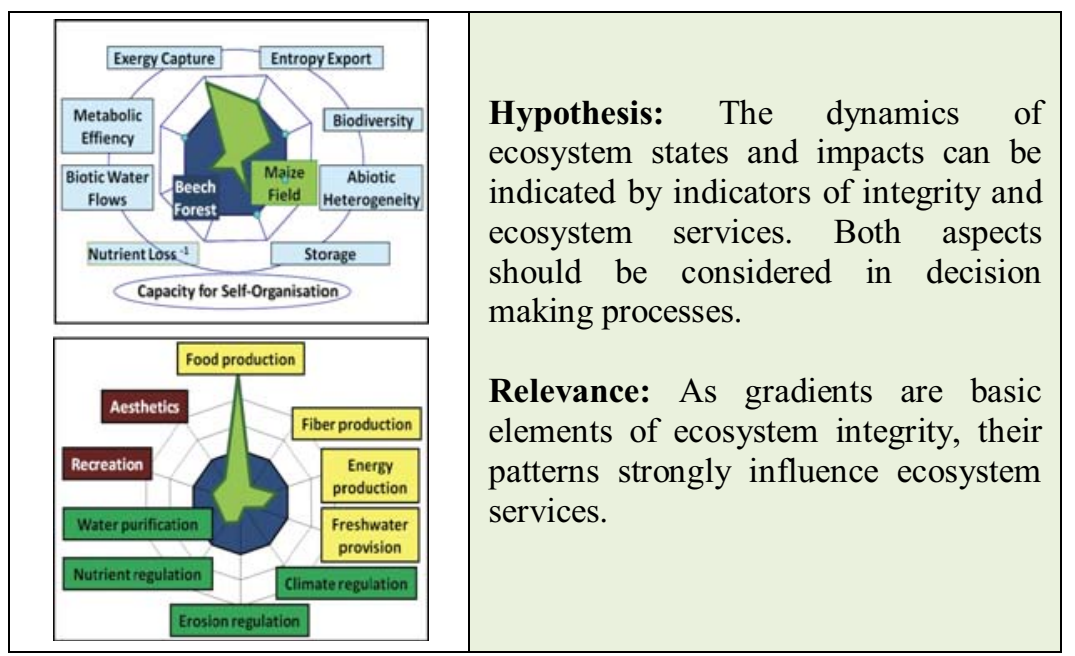

Figure 12: Illustrating the necessity to indicate both environmental DPSIR components.

can be provided by this approach, but we have also seen that focusing on services alone is not sufficient and that monetization may lead to non-satisfactory results. The problem is that a nature-near state (bright area) with high orientor values does produce a high amount of regulating and cultural services. But most of them are related to non-market values, whereas the agricultural productivity can easily be measured and accounted. Thus service valuation strongly depends on the respective evaluator, and the methods to quantify public goods like regulation or aesthetic services seem to be underdeveloped and arbitrary at the moment. Of course this can change in the future. Nevertheless, the inclusion of ecological information on the service providing potentials and their change for example under certain scenario conditions seems to be a topical and consequent step, i.e. if we understand the services as human benefits which arise from ecosystem performance, integrity, and organization.

Finally a direct transcription of the ecological orientor approach to human and human-environmental systems, with which we are returning to the initial discussions on self-organizational potentials, will be proposed. In a very interdisciplinary context, Bossel has developed a target-related orientor theory which is applicable for all types of self-organized systems. Therefore his concept of basic orientors [73-75] can be used to characterize human systems with the same criteria as environmental units. The idea is that all self-organized systems have to cope with similar challenges, which determine their behavior. Thus, there are some focal properties and necessities of a system's environment which demand for certain solutions. Bossel [73] has listed the following main challenges:

- To maintain a normal environmental state,

- To cope with resource scarcity,

- To proceed in spite of environmental variety and variability,

- To react after changes of constraints,

- To account for other related systems.

In a subsequent step Bossel [73] has identified six basic orientors for each self-organizing system (see Fig. 13). These are documented in Table 5. In addition to them, he has selected three basic 


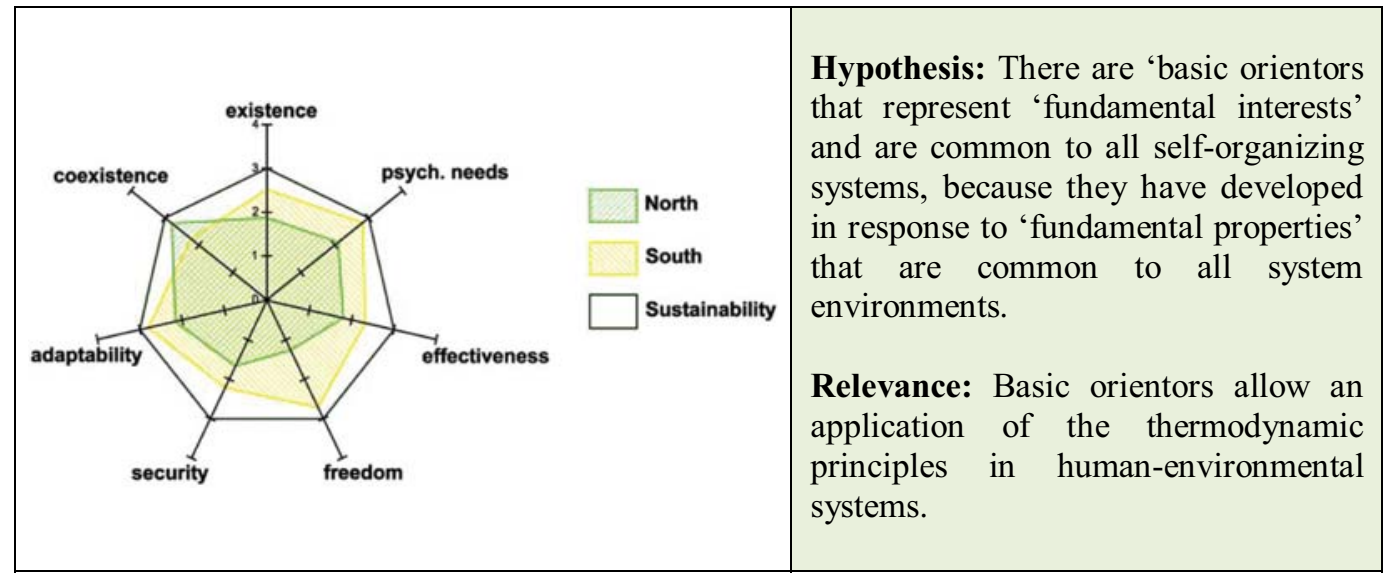

Figure 13: Illustrating the concept of basic orientors. The left side includes a comparison of different country types referring to the single orientors after Bossel [73].

Table 5: Basic orientors after Bossel [73, 74] and Omann [76].

\begin{tabular}{ll}
\hline Basic orientor & \multicolumn{1}{c}{ Explanation } \\
\hline Existence & $\begin{array}{l}\text {...ensures survival and subsistence of the system in the normal } \\
\text { environmental state. } \\
\text {...enables the system to be effective to secure scarce resources } \\
\text { Effectiveness }\end{array}$ \\
$\begin{array}{l}\text { Freedom of action } \\
\text { envides the opportunity to deal with challenges posed by the } \\
\text { Security }\end{array}$ & $\begin{array}{l}\text {...enables the system to protect structures and functions. } \\
\text { Adaptability } \\
\text { chakes it possible to adapt to challenges posed by environmental } \\
\text { change. }\end{array}$ \\
Coexistence & $\begin{array}{l}\text { enables the system to adapt its behavior in response to the } \\
\text { behavior and interests of other related systems. }\end{array}$ \\
\hline
\end{tabular}

orientors which are relevant for self-reproducing, sentient, and conscious beings - e.g. human system. They are: (i) psychological needs, (ii) responsibility, and (iii) reproduction [76, 77].

Following this theory, the basic orientors are valid for all self-organizing systems, independent of special characteristics, such as size, elements, or relations. If the orientors are satisfied, the system is fit and has a better chance of achieving sustainability [74]. Satisfaction of the orientors must apply to all subsystems of the system considered. Thus orientors can be used to characterize a system's viability due to the degree of satisfaction of all orientors. The basic orientors are unique for all systems, "because they have developed in response to certain 'fundamental properties' that are common to all system environments" ([73], p. 339).

These orientors are highly correlated with gradients: while the existence orientor demands a longterm maintenance of the internal gradients of stocks and resources, the effectiveness orientor describes the loss minimization during transfers between gradients, which is typical for developing ecosystems. The component freedom of action is related to the resilience of the gradient system, and security 
is a measure to protect the performance and the existence of the system. Adaptability has been defined by Müller et al. (2010) [65] as follows: a system has a high adaptability if the sum of all disturbances and changes in the attractor domains do not reduce the system's degree of self-organization. Thus it is strongly related to Bossel's coexistence orientor. In a linked article [2] the connections between gradients and basic orientors are analyzed using rural-urban profiles as case studies.

\section{CONCLUSIONS}

In this article, we have touched a high number of different scientific and management approaches to test their interrelations with the ecological gradient principle. Summarizing these concepts and linkages, it can be stated that:

- Ecosystem self-organization is connected with the creation of gradients and hierarchies.

- Gradients are causes for and results from ecological self-organization. Thus, they can be designated as emergent properties of ecosystems [78] and used as indices for the autocatalytic potential of ecological entities.

- Gradients are products of the interactions between creative and destructive ecological processes. They are consequences of accumulating processes on the one hand (gradient creation) and fundamentals for eroding processes on the other (gradient degradation).

- Gradients operate on distinct ecological scales. Between these scales, certain mechanisms of selfregulation determine ecosystem development.

- Gradients develop as ecological orientors. Their size, extend, diversity, and the eco-physiological linkages between them are successional objects that are optimized throughout undisturbed ecosystem dynamics. Therefore, gradients can be used as fundamentals for the indication of developmental ecological states.

- Thermodynamic principles and network analyses can help to understand the pathways of ecosystem development, including the elaboration of ecological orientors.

- Orientors can be used to derive systems-based indicator systems to depict integrity and adaptability referring to the self-organization capacity of environmental systems.

- These indicators can be integrated into human-environmental systems analysis. In this context gradients can be correlated with the concept of basic orientors.

- Management should attempt to optimize the adaptability of environmental systems, taking into account the potential of ecosystems to continue self-organized process sequences and offering these systems the necessary degrees of freedom for such development.

- Due to the thermodynamic constraints, the respective guidelines should support the ecosystems' abilities to capture energy, to store nutrients and energy and optimize information, to transfer the maintenance products into the environment in a healthy manner, to increase diversity, heterogeneity, and connectedness, to optimize internal flows and cycles and to reduce losses, to unfold a diverse hierarchy of gradients, and to optimize the provision of ecosystem services.

- Gradients are suitable instruments to couple different ecological theories and to combine them with empirical and practical investigations.

Coming back to the initial citation of Tiezzi [1] from the introduction, it can be conformed that pattern formation is strongly linked to the creation of gradients. These processes operate on all hierarchical levels, therefore the gradient ideas could be developed further to elaborate indicators with a similar dimension on different scales to better understand the enormous complexity of environmental systems. 


\section{REFERENCES}

[1] Tiezzi, E., Steps Towards an Evolutionary Physics, WIT Press: Southampton, 2006.

[2] Kroll, F. \& Müller, F., Can the principle of gradients be applied for human systems? A case study on rural-urban interactions. International Journal of Design \& Nature and Ecodynamics, 6(4), (in press).

[3] Prigogine, I., Order through fluctuations: self organization and social system. Evolution and Consciousness: Human Systems in Transition, eds E. Jantsch \& C.H. Waddington, AddisonWesley: Reading, MA, pp. 94-108, 1976.

[4] Prigogine, I., From Being to Becoming, Freeman: San Francisco, 1980.

[5] Joergensen, S.E., Integration of Ecosystem Theories: A Pattern, Dortrecht: Kluwer, 1992.

[6] Nicolis, G. \& Prigogine, I., Self-organization in non-equilibrium systems: from storage in plants. Annu. Rev. Ecol. Systems, 21, pp. 423-447, 1977.

[7] Nicolis, G. \& Prigogine, I., Exploring Complexity: An Introduction, W.H. Freeman and Co: New York, 1989.

[8] Prigogine, I. \& Stengers, I., Order Out of Chaos, Flamingo: London, 1984.

[9] Haken, H., Synergetics, an Introduction, Springer: Berlin, 1983.

[10] Schneider, E.D. \& Kay, J., Life as a manifestation of the second law of thermodynamics. Math. Comput. Modelling, 19, pp. 25-48, 1994. doi:http://dx.doi.org/10.1016/0895-7177(94)90188-0

[11] Tiezzi, E., The End of Time, WIT Press: Southampton, 2002.

[12] Touring, A.M., The chemical basis of morphogenesis. Phil. Trans. R: Soc London B, 327, pp. 37-52, 1952. doi:http://dx.doi.org/10.1098/rstb.1952.0012

[13] Rosen, D., Kim, J.H. \& Nam, Y., Birds of a Feather protest together: theorizing self-organizing political protests with flock theory. Syst Pract Action Res, 23, pp. 419-441, 2010. doi:http:// dx.doi.org/10.1007/s11213-010-9167-3

[14] Eigen, M., Selforganisation of matter and the evolution of biological macromolecules. Naturwissenschaften, 58, pp. 465-523, 1971. doi:http://dx.doi.org/10.1007/BF00623322

[15] Kauffmann, S., The Origins of Order: Self-Organization and Selection in Evolution, Oxford University Press: New York, 1993.

[16] Lovelock, J.E., Gaia: A New Look at Life on Earth, Oxford University Press: New York, 1979.

[17] Schneider, E. \& Sagan, D., Into the Cool - Energy Flow, Thermodynamics and Life, University of Chicago Press: Chicago, IL, 2005.

[18] Müller, F. \& Joergensen, S.E., Ecological orientors: a path to environmental applications of ecosystem theories. Handbook of Ecosystem Theories and Management, eds S.E. Joergensen \& F. Müller, CRC Publishers: Boca Raton, FL, pp. 561-576, 2000.

[19] Müller, F., Breckling, B., Bredemeier, M., Grimm, V., Malchow, H., Nielsen. S.N. \& Reiche, E.W., Ökosystemare Selbstorganisation. Handbuch der Ökosystemforschung, eds O. Fränzle, F. Müller \& W. Schröder, Landsberg, 1997.

[20] An der Heiden, U., Selbstorganisation in dynamischen Systemen. Emergenz: Die Entstehung von Ordnung, Organisation und Bedeutung, eds W. Krohn \& G. Küppers, Suhrkamp: Frankfurt, 1992.

[21] Ebeling, W., Chaos - Ordnung - Information, Verlag Harri Deutsch: Frankfurt, 1989.

[22] Krohn, W. \& Küppers, G., Emergenz: Die Entstehung von Ordnung, Organisation und Bedeutung, Suhrkamp-Taschenbuch: Frankfurt, 1992.

[23] Roth, G., Gehirn und Selbstorganisation. Emergenz: Die Entstehung von Ordnung, Organisation und Bedeutung, eds W. Krohn \& G. Küppers, Suhrkamp: Frankfurt, 1990.

[24] Salthe, S.N., Development and Evolution: Complexity and Change in Biology, MIT Press: Cambridge, 1993. 
[25] Von Förster, H., Kausalität, Unordnung, Selbstorganisation. Grundprinzipien der Selbstorganisation, eds K.W. Kratky \& F.F. Wallner, Wiss. Buchges: Darmstadt, 1990.

[26] Joergensen, S.E., Fath, B., Bastianoni, S., Marquez, J., Müller, F., Nielsen, S.N., Patten, B., Tiezzi, E. \& Ulanowicz, R., A New Ecology - The Systems Perspective, Elsevier Publishers: Amsterdam, 2007.

[27] Müller, F. \& Nielsen, S.N., Ecosystems as subjects of self-organized processes. Handbook of Ecosystem Theories and Management, eds S.E. Joergensen \& F. Müller, CRC Publishers: Boca Raton, FL, pp. 177-194, 2000.

[28] Whittaker, R.H., Evolution of species diversity in land communities. Evol. Biol, 10, pp. 1-67, 1977.

[29] Gosz, J.R., Gradient analysis of ecological change in time and space: implications for forest management. Ecological Applications, 2, pp. 248-261, 1992. doi:http://dx.doi. org/10.2307/1941859

[30] Brown, J.H., Macroecology, University of Chicago Press: Chicago, IL, 1995.

[31] Fränzle, O., Die Struktur und Belastbarkeit von Ökosystemen. Tagungsberichte und wissenschaftliche Abhandlungen 41, Deutscher Geographentag: Mainz, pp. 469-485, 1978.

[32] Kay, J.J., Ecosystems as self-organised holarchic open systems: narratives and the second law of thermodynamics. Handbook of Ecosystem Theories and Management, eds. S.E. Joergensen \& F. Müller, CRC Publishers: Boca Raton, FL, pp. 135-160, 2000.

[33] Müller, F., Gradients in ecological systems. Proceedings of the Eco-Summit 1996 in Copenhagen. Ecological Modelling, 108, pp. 3-21, 1998.

[34] Müller, F. \& Fath, B., The physical basis of ecological goal functions. Eco Targets, Goal Functions and Orientors, eds F. Müller \& M. Leupelt, Springer: Berlin, pp. 269-285, 1997.

[35] Golley, F., Ecosystem structure. Handbook of Ecosystem Theories and Management, eds S.E. Joergensen \& F. Müller, CRC Publishers: Boca Raton, FL, pp. 21-32, 2000.

[36] Müller, F. \& Windhorst, W., Ecosystems as functional entities. Handbook of Ecosystem Theories and Management, eds S.E. Joergensen \& F. Müller, CRC Publishers: Boca Raton, FL, pp. 33-50, 2000.

[37] Odum, H.T., Systems Ecology, Wiley: New York, 1983.

[38] Ulanowicz, R.E., Ascendency: a measure of ecosystem performance. Handbook of Ecosystem Theories and Management, eds S.E. Joergensen \& F. Müller, CRC Publishers: Boca Raton, FL, pp. 303-316, 2000.

[39] Svirezhev, Y.M. \& Steinborn, W., Exergy of solar radiation: thermodynamic approach. Ecological Modelling, 145, pp. 101-110, 2001. doi:http://dx.doi.org/10.1016/ S0304-3800(01)00409-4

[40] Kutsch, W., Dilly, O., Steinborn, W. \& Müller, F., Quantifying ecosystem maturity - a case study. Eco Targets, Goal Functions, and Orientors, eds F. Müller \& M. Leupelt, SpringerVerlag: Berlin, pp. 209-231, 1998. doi:http://dx.doi.org/10.1007/978-3-642-58769-6 13

[41] Müller, F., Fränzle, O. \& Schimming, C., Ecological gradients as causes and effects of ecosystem organization. Ecosystem Organization of a Complex Landscape, eds O. Fränzle, L. Kappen, H.-P. Blume \& K. Dierssen, Ecological Studies Vol. 202, Springer-Verlag: Berlin, pp. 277-296, 2008.

[42] Patten, B. C., Network ecology: indirect determination if the life-environment relationship in ecosystems Theoretical Studies of Ecosystems, eds M. Higashi \& T.P. Burns, Cambridge University Press: Cambridge, 1991.

[43] Ulanowicz, R.E., Growth and Development: Ecosystems Phenomenology, Berlin, 1986. 
[44] O'Neill R.V., De Angelis, D.L., Waide, J.B., Allen, T.H.F., A Hierarchical Concept of Ecosystems, Monographs in Population Ecology 23, Princeton University Press: Princeton, NJ, 1986.

[45] Allen, T.F.H. \& Starr, T. B., Hierarchy: Perspectives for Ecological Complexity, University of Chicago Press: Chicago, IL, 1982.

[46] Allen, T.F.H. \& Hoekstra, T.W., Toward a Unified Ecology, Columbia University Press: New York, 1992.

[47] Müller, F., Hierarchical approaches to ecosystem theory. Ecol. Model., 63, pp. 215-242, 1992. doi:http://dx.doi.org/10.1016/0304-3800(92)90070-U

[48] Joergensen, S.E., The tentative fourths law of thermodynamics. Handbook of Ecosystem Theories and Management, eds S.E. Joergensen \& F. Müller, CRC Publishers: Boca Raton, FL, pp. 161-176, 2000.

[49] Fath, B. \& Patten, B.C., Network orientors: a utility goal function based on network synergism. Eco Targets, Goal Functions and Orientors, eds F. Müller \& M. Leupelt, Springer: Berlin, pp. 161-176, 1998.

[50] Patten, B.C., Environs: relativistic elementary particles for ecology. American Naturalist, 119, pp. 179-219, 1982. doi:http://dx.doi.org/10.1086/283903

[51] Patten, B.C., Energy, emergy, and environs. Ecological Modelling, 62, pp. 29-70, 1992. doi:http://dx.doi.org/10.1016/0304-3800(92)90081-O

[52] Ulanowicz, R.E., Ecology, the Ascendent Perspective, Columbia University Press: New York, 201, 1997.

[53] Higashi, M. \& Burns, T., Theoretical Studies of Ecosystems: The Network Perspective, Cambridge University Press: Cambridge, 1991.

[54] Odum, E.P., The strategy of ecosystem development. Science, 164, pp. 262-270, 1969. doi:http://dx.doi.org/10.1126/science.164.3877.262

[55] Müller, F. \& Leupelt, M., Eco Targets, Goal Functions, and Orientors, Springer-Verlag: Berlin, 1997.

[56] Fath, B. \& Patten, B.C., Ecosystem theory: network environ analysis. Handbook of Ecosystem Theories and Management, eds S.E. Joergensen, F. Müller, CRC Publishers: Boca Raton, FL, pp. 345-360, 2000.

[57] Vitousek,P.M., Beyond global warming: ecology and global change. Ecology, 75, pp. 1861-1876, 1994. doi:http://dx.doi.org/10.2307/1941591

[58] Di Castri, F. \& Hadley, M., Enhancing the credibility in ecology: interacting along and across hierarchical scales. Geo J., 17, pp. 5-35, 1988.

[59] Picket, S.T.A. \& White, P.S., The Ecology of Disturbance and Patch Dynamics, Academic Press: New York, 1985.

[60] Holling, C.S., The resilience of terrestrial ecosystems: local surprise and global change. Sustainable Development of the Biosphere, eds W.M. Clark \& R.E. Munn, Cambridge University Press: Cambridge, UK, pp. 292-320, 1986.

[61] Müller, F. \& Burkhard, B., Ecosystem indicators for the integrated management of landscape health and integrity. Handbook of Ecological Indicators for Assessment of Ecosystem Health, 2nd edn, eds S.E. Jorgensen, L. Xu \& R. Costanza, Taylor \& Francis: London, pp. 391-423, 2010.

[62] Gundersson, L.H. \& Holling, C., Panarchy, Island Press: Washington, DC, 2002.

[63] Jorgensen, S.E., Xu, L., Costanza, R. (eds.), Handbook of Ecological Indicators for Assessment of Ecosystem Health, 2nd edn, Taylor \& Francis: London, 2010.

[64] Burkhard, B., Müller, F. \& Lill, A., Ecosystem health indicators. Encyclopedia of Ecology, eds S.E. Joergensen \& B. Fath, Elsevier Publishers: Amsterdam, 2008. 
[65] Müller, F., Burkhard, B. \& Kroll, F., Resilience, integrity and ecosystem dynamics: bridging ecosystem theory and management. Landform - Structure, Evolution, Process Control, eds J.-C. Otto \& R. Dikau, Lecture Notes in Earth Sciences Series, Vol. 115, Springer: Heidelberg, pp. 221-242, 2010.

[66] Burkhard, B. \& Müller, F., Drivers-pressure-state-impact-response. Vol. [2] of Encyclopedia of Ecology, eds S.E. Jørgensen \& B.D. Fath, Elsevier: Oxford, 5 vols edition, pp. 967-970, 2008.

[67] Müller, F., Indicating ecosystem and landscape organization. Ecological Indicators, 5(4), pp. 280-294, 2005. doi:http://dx.doi.org/10.1016/j.ecolind.2005.03.017

[68] Kay, J.J., Self-Organization and the Thermodynamics of Living Systems: A Paradigm, PhD Thesis, University of Waterloo, Canada 1983.

[69] Fränzle, O., Kappen, L., Blume, H.-P. \& Dierssen, K. (eds), Ecosystem Organization of a Complex Landscape, Ecological Studies, Vol. 202, Springer-Verlag: Berlin, 2008.

[70] Schrautzer, J., Müller, F., Blume, H.-P., Heinrich, U., Reiche, E.W., Schleuss U. \& Dierssen, K., An indicator-based characterization of the Bornhöved key ecosystems. Ecosystem Organization of a Complex Landscape, eds O. Fränzle, L. Kappen, H.-P. Blume \& K. Dierssen, Ecological Studies, Vol. 202, Springer-Verlag: Berlin, pp. 297-318, 2008.

[71] Kumar, P. (eds), The Economics of Ecosystems and Biodiversity, Earthscan: London, 2010.

[72] Burkhard, B., Müller, F., Kroll, F. \& Windhorst, W., Landscapes' capacities to provide ecosystem services - a concept for land-cover based assessments. Landscape Online, Edition $15 / 2009$.

[73] Bossel, H., Policy assessment and simulation of actor orientation for sustainable development. Ecological Economics, 34, pp. 337-355, 2000. doi:http://dx.doi.org/10.1016/S0921$\underline{\text { 8009(00)00218-4 }}$

[74] Bossel, H., Deriving indicators of sustainable development. Environmental Modeling and Assessment, 1, pp. 193-218, 1996. doi:http://dx.doi.org/10.1007/BF01872150

[75] Bossel, H., Ecological orientors: emergence of basic orientors in evolutionary self-organization. Eco Targets, Goal Functions and Orientors, eds F. Müller \& M. Leupelt, Springer: Berlin, pp. 19-33, 1998.

[76] Omann, I., Multi-criteria Decision Aid as an Approach for Sustainable Development Analysis and Implementation, Diss., University of Graz, 2004.

[77] Spangenberg, J.H., Die ökonomische Nachhaltigkeit der Wirtschaft, Edition Sigma: Berlin, 2005.

[78] Nielsen, S.N. \& Müller, F., Emergent properties of ecosystems. Handbook of Ecosystem Theories and Management, eds S.E. Joergensen \& F. Müller, CRC Publishers: Boca Raton, FL, pp. 195-216, 2000.

[79] Kay, J.J., 1993, "On the Nature of Ecological Integrity: Some Closing Comments" in S. Woodley, J. Kay, G. Francis (Eds.), 1993. Ecological Integrity and the Management of Ecosystems, St. Lucie Press, Delray, Florida, pp. 201-212. 